\title{
CÓMO NARRAR EL DESARROLLO DE LA FILOSOFÍA DE LA CIENCIA EN EL SIGLO XX. RESPUESTA A ALEJANDRO CASSINI
}

\author{
C. Ulises Moulines \\ Universidad de Múnich \\ moulines@lrz.uni-muenchen.de
}

En el artículo de Alejandro Cassini, "Sobre la historia de la filosofía de la ciencia. A propósito de un libro de C. Ulises Moulines", pueden distinguirse claramente dos partes. La primera es un extenso análisis crítico de mi libro El desarrollo moderno de la filosofía de la ciencia (1890-2000); la segunda, más breve, está contenida en la sección 6 (la última) de su artículo, y en ella el profesor Cassini esboza algunas maneras alternativas posibles de construir un relato sobre el desarrollo de la filosofía de la ciencia. Dado que esta última parte tiene el carácter de un esbozo y es, de hecho, independiente de lo que expongo en mi libro, no me extenderé sobre ella, aunque al final haré algunas breves observaciones al respecto. Lo que más me interesa aquí es responder a las críticas por así decir inmanentes que me hace Cassini y que se refieren a las supuestas lagunas o insuficiencias de mi exposición.

Cassini resume adecuadamente los aspectos esenciales de mi relato historiográfico y hace una serie de observaciones interesantes, a las que me complace tener la oportunidad de responder. Con algunas de ellas estoy plenamente de acuerdo, con otras lo estoy a medias y con otras, en fin, no lo estoy en absoluto. Supongo que el propio Cassini no esperaba otra cosa. Él mismo lo da a entender:

\footnotetext{
Sería [... ingenuo pensar que existe un relato correcto o privilegiado de la historia. Hay siempre varios relatos diferentes compatibles con toda la información disponible en un momento dado, del mismo modo que hay muchas teorías posibles capaces de acomodar toda la evidencia conocida. Además, las diferencias de selección, valoración e interpretación se reflejarán inevitablemente en narrativas diferentes, aunque no necesariamente incompatibles entre sí.
}

Puedo suscribir cada una de las palabras de esta cita. En efecto, si sabemos por la historia general que un mismo evento o proceso 
histórico (pongamos por caso, la Segunda Guerra Mundial) se puede interpretar de maneras diferentes, algunas claramente compatibles entre sí, otras menos, pero todas ellas más o menos verosímiles respecto de los datos disponibles, ello también vale para la historia de las ideas, y más particularmente aún para la historia de la filosofía de la ciencia, una historia que, por cierto, está aún en gran medida por escribir, como el propio Cassini advierte. Si es válida la Tesis de la Subdeterminación de la Teoría por la Experiencia en el caso de la Física y otras ciencias naturales, tanto más válida será aún lo que podríamos denominar la "Tesis de la Subdeterminación de la Historiografía por la Historia". Respecto de una misma serie de eventos históricos, un historiador enfatizará unos aspectos y otro historiador otros, según ciertos baremos distintos, respectivamente adoptados por uno y otro, para valorar lo que cada uno considera lo más esencial o "más profundo". Esto es perfectamente legítimo. En cambio, no lo sería un relato que deformara o simplificara el material histórico hasta tal punto que resultara irreconocible o inverosímil. Para seguir con el ejemplo de la Segunda Guerra Mundial, es legítimo que un determinado historiador ponga el énfasis en los aspectos geopolíticos (rivalidad por el dominio de Europa y del Pacífico), y otro lo haga en los ideológicos (fascismo contra comunismo y democracia). Pero lo que sería claramente inaceptable es, pongamos por caso, que alguien le atribuyera toda la responsabilidad de la Segunda Guerra Mundial a Neville Chamberlain, o bien ignorara la destrucción masiva de las ciudades alemanas por los Aliados. En otras palabras, hay ciertos límites a la flexibilidad inherente a la "subdeterminación".

Pues bien, dado que Cassini y yo parecemos estar perfectamente de acuerdo sobre esta "Tesis de la Subdeterminación de la Historiografía por la Historia", me es más difícil comprender la base de algunas de las críticas que me hace, las cuales justamente parecen contradecir la tesis mencionada. Es decir, no me queda claro en muchos casos si las divergencias que muestra Cassini respecto de mi relato pertenecen a la primera categoría de las ejemplificadas arriba (divergencias de énfasis, sobre las cuales no cabe sino tomar una actitud de tolerancia) o bien a la segunda (interpretación muy inverosímil o negligencia de elementos esenciales, lo cual el historiador criticado, en el presente caso yo mismo, sí debería tomar muy en serio). Por si acaso, trataré de acotar lo mejor posible el ámbito de nuestras divergencias para tratar de determinar su naturaleza.

Para empezar, quizás no sea ocioso recordar dos características de mi libro que son manifiestas para cualquier lector y que reducen la 
pertinencia de algunas críticas que me hace Cassini. La primera característica es que, como explico en el prólogo, mi texto está dirigido fundamentalmente no a especialistas en filosofía de la ciencia, sino a un público no especializado (lectores de los que sólo presupongo un mínimo bagaje filosófico y casi ninguno de las ramas más técnicas de la filosofía, como la lógica y la filosofía formal de la ciencia). En consecuencia, mi dibujo del desarrollo de la filosofía de la ciencia está trazado deliberadamente con, por así decir, "trazos gruesos". De ahí que no considere pertinentes algunas críticas (menores) que me hace Cassini; por ejemplo, la de que, entre los precursores de la moderna filosofía de la ciencia, yo no mencione a autores (realmente secundarios para nuestra historia) como Vaihinger o Meyerson, o bien que, al tratar del tema de la eliminabilidad de los términos teóricos, me refiera al método de Ramsey pero no al teorema de Craig. ${ }^{l}$ Sin duda muchos otros autores y temas que yo no menciono podrían discutirse en una exposición completa de la filosofía de la ciencia del siglo XX; pero obviamente ellos no cabrían en un texto de menos de 200 páginas, sino que requerirían de un tratado de por lo menos el doble o el triple de extensión.

La otra característica manifiesta de mi libro, que aparece explícitamente en el título, es que se trata de relatar la historia de la filosofía de la ciencia hasta el año 2000, y no después. En realidad, mi ideal habría sido poner como fecha límite 1990, porque estoy convencido de que, en la historia de las ideas, hay que adoptar una perspectiva distante de por lo menos quince o veinte años (creo que la mayoría de historiadores estaría de acuerdo conmigo). De lo contrario corremos el riesgo de dejarnos deslumbrar por las modas efímeras del momento. Pero el editor alemán de mi libro insistió en que "redondeara" la fecha límite al año 2000, cosa que acepté a regañadientes. Ésta es la base de mi respuesta a una de las críticas más detalladas que me hace Cassini: que en mi libro hago escasa mención de la nueva corriente de la "filosofía de la experimentación" (al parecer, un enfoque especialmente caro a Cassini). Mi respuesta concreta a ello es la siguiente. Es cierto que la filosofía de la experimentación es bastante

${ }^{1}$ El teorema de Craig es un asunto muy técnico, cuya comprensión requiere muy sólidos conocimientos de lógica formal. Ya bastante me costó en mi texto tratar de explicar de manera lo más informal posible el quid del enunciado de Ramsey (no sé si lo logré); añadir a ello una explicación intuitiva del teorema de Craig habría rebasado con mucho mis capacidades didácticas... Por lo demás, es un hecho histórico que el teorema de Craig, a diferencia del método de Ramsey, tuvo muy escasa incidencia en la discusión posterior. En filosofía de la ciencia, del enunciado de Ramsey se sigue hablando hasta el día de hoy, del teorema de Craig no. 
popular en la actual filosofía de la ciencia (aunque a mi parecer, está sobrevalorada, pero ésa es otra cuestión); y también es cierto que las raíces para esta nueva corriente se encuentran en las dos últimas décadas del siglo XX. Pero en esos años no tuvo ni de lejos un papel comparable al de los otros enfoques y autores que analizo en el último capítulo de mi libro (concepciones semánticas, especialmente van Fraassen, estructuralismo, Cartwright, unificacionismo en la teoría de la explicación, realismo estructural...). Para convencerse de ello basta echarle una ojeada a los artículos publicados en esos años en revistas como Philosophy of Science, Synthese, Erkenntnis etc. o en las antologías y actas de congresos más divulgadas. Dicho esto, la impresión que comunica Cassini de que ignoro el "giro experimental" en la filosofía de la ciencia me parece improcedente: al fin y al cabo, no sólo menciono a dos pioneros de ese giro (Franklin y Galison), sino que, además, al máximo adalid de dicha corriente, Ian Hacking, le dedico una exposición relativamente detallada (cuatro páginas y media, más de lo que le dedico a Popper, por ejemplo, algo por lo que sin duda los popperianos que aún existan nunca me perdonarán... ). Si así lo hice (a pesar de mis escasas simpatías por dicha corriente, lo confieso), fue justamente porque quería indicarle al lector que el "experimentalismo" de Hacking iba a tener una notable influencia posterior.

Las otras dos críticas de peso que me hace Cassini se refieren, la primera, a la cronología para el desarrollo de la filosofía de la ciencia que propongo en mi libro, la otra, al énfasis, exagerado según él, puesto en el último capítulo en las concepciones semánticas o "modelísticas" (Cassini no distingue claramente entre ambos términos) para las últimas décadas del siglo XX en detrimento de otras corrientes igualmente influyentes. Empecemos por la cuestión cronológica. En mi libro divido el material histórico examinado en cinco fases (no periodos) desde finales del siglo XIX hasta finales del XX. Como explico en la introducción, prefiero el término "fase" al de "periodo", pues el primero admite traslapes cronológicos sustanciales. La primera objeción que me hace Cassini respecto de la cronología se refiere al inicio de nuestra disciplina. Yo lo fecho alrededor de 1890, cuando se instituyó en Viena la primera cátedra de filosofía de la ciencia en un sentido moderno; en cambio, Cassini propone una fecha mucho más tardía, alrededor de $1935 .^{2} \mathrm{Su}$ argumentación para

\footnotetext{
${ }^{2}$ Curiosamente, otro autor que acaba de publicar una reseña de mi libro en esta misma revista, Alfonso Ávila del Palacio, propone una "fecha de nacimiento" considerablemente anterior: la obra de Kant a finales del siglo XVIII, y ofrece algunos
} 
ello es que el término "philosophy of science" empieza a divulgarse sólo a partir de mediados de la década de 1930, y que sólo a partir de esa época empieza a haber revistas y congresos explícitamente dedicados a la filosofía de la ciencia. Esta argumentación no me parece muy convincente: si bien es cierto que, en el mundo anglosajón, sólo empieza a usarse "philosophy of science" en esos años, en cambio, el término equivalente alemán, "Wissenschaftstheorie", se usaba ya en las décadas anteriores, y lo mismo puede decirse del término francés "épistémologie". Además, el hecho de que la denominación de una disciplina aún no se haya estabilizado en una época determinada, no implica que, para el historiador, ella no sea identificable con anterioridad. Así, por ejemplo, la denominación "física" para la disciplina que así conocemos hoy día, no se estabilizó en Occidente sino hasta el siglo XIX. (Antes era habitual denominarla "filosofía natural", recuérdese el título del opus magnum de Newton.) Ello no implica que la física en un sentido moderno no existiera ya desde Galileo o incluso antes. Algo análogo puede decirse de la divulgación de revistas y congresos exclusivamente dedicados a una disciplina: en la historia de la ciencia, ello suele darse en época bastante posterior al surgimiento de la disciplina en cuestión. En mi opinión, el criterio esencial para fechar el nacimiento de una disciplina es que empiecen a percibirse y tratarse sus temas específicos; y en el caso de la filosofía de la ciencia ello acaeció a fines del siglo XIX con la institución de la cátedra que primero ocupó Ernst Mach y con la publicación de las obras del propio Mach, de Peirce, Poincaré, Duhem, Russell y otros en los años precedentes a la Primera Guerra Mundial, y poco después con la constitución del Círculo de Viena, la Escuela de Berlín y otros grupos afines que discutieron temas y métodos que hoy en día reconocemos como típicos de nuestra disciplina. Es claro que todo ello ocurrió antes de 1935.

El otro desacuerdo cronológico manifestado por Cassini se refiere a la última fase identificada en mi libro, que va más o menos de 1970 a 2000. Yo la bauticé, a falta de término mejor, con el neologismo "modelística", pues en muchas corrientes de esa fase la noción de modelo (en sus diversas, pero emparentadas, acepciones) tiene gran relevancia. Al respecto, Cassini me hace dos objeciones: 1) las raíces del "modelismo" en la filosofía de la ciencia están ya en los escritos de Patrick Suppes de los años 1950-1960, de modo que el traslape

argumentos dignos de consideración a favor de esa propuesta. En cualquier caso, me consuela constatar que mi elección se encuentra, por así decir, a medio camino entre las de estos dos críticos. ¿Será que, como decía Aristóteles, la verdad está en el justo medio...? 
cronológico entre lo que yo caracterizo como fase modelística con las fases clásica e historicista es mucho mayor de lo que yo sugiero; 2) hay un número considerable de corrientes en las últimas décadas del siglo XX en las que la noción de modelo apenas tiene algún papel. Le concedo a Cassini la pertinencia de estas dos objeciones, aunque sólo parcialmente. Las razones por las que mi acuerdo con Cassini es sólo parcial son las siguientes. Respecto a la objeción 1), es indudable que ya en los años 1950 Suppes propone un cambio sustancial de metodología en el análisis de las teorías científicas, donde la noción de modelo resulta central y prefigura las concepciones típicamente modelísticas posteriores (representacionalismo, concepciones semánticas, estructuralismo, etc.). Así lo explico yo mismo en mi libro (pp. 112 y ss.). Por otro lado, no obstante, creo que una ojeada imparcial a la bibliografía sobre las grandes controversias en la filosofía de la ciencia de los años 1950 y 1960 muestra que las publicaciones de Suppes en esos años tienen un papel muy marginal, o son simplemente ignoradas. Fue sólo a partir de los años 1970, gracias al énfasis puesto por autores como van Fraassen, Suppe, Sneed y otros, que la metodología suppesiana se empieza a ver no sólo como una cómoda técnica para axiomatizar teorías empíricas, sino como una base muy importante para discutir problemas epistemológicos de mayor alcance.

Respecto de la objeción 2) de Cassini, reconozco que algunas de las corrientes y discusiones características de las últimas décadas del siglo XX tienen poco o nada que ver con una visión modelística de las teorías científicas. Esto es particularmente cierto de las controversias alrededor del tema de la explicación científica. De hecho, si hoy en día volviera a escribir mi libro, dividiría el último capítulo en dos: uno dedicado al modelismo representado por la Escuela de Stanford, el representacionalismo, las concepciones "semánticas" sensu stricto de van Fraassen, Suppe y Giere, y el estructuralismo; el otro estaría dedicado a todo lo demás (los semirrealismos experimentalistas de Cartwright y Hacking, el realismo estructural y los diversos enfoques sobre la explicación científica, por lo menos; probablemente añadiría ahora una exposición del neobayesianismo). Dicho esto, incluso en el caso del último grupo de enfoques, no estoy seguro de que en muchos de ellos no pueda detectarse una presuposición, al menos implícita, de ideas modelísticas. Esto me parece bastante claro en Cartwright (discípula de Suppes), y también en Worrall y sus seguidores: las "estructuras" de las que ellos hablan como pivote del desarrollo de la ciencia no son otra cosa que modelos en un sentido igual o próximo al de enfoques típicamente modelísticos como el estructuralismo. En 
realidad, me parece que el propio Cassini está dispuesto a reconocer la centralidad del concepto de modelo incluso para concepciones que no son "oficialmente" modelísticas cuando escribe: "muchos filósofos de la ciencia [de las últimas décadas] han prácticamente reemplazado la noción [clásica] de teoría por la de modelo". Esta constatación corresponde al espíritu, si no a la letra, de lo que expongo en el último capítulo de mi libro. Para la gran mayoría de los enfoques que allí analizo, incluido el estructuralismo al que me adhiero, es el caso que si bien todavía usan el término "teoría", es porque para ellos una teoría es una colección de modelos.

Ello me lleva, para finalizar esta réplica, a tratar de una crítica más sustancial que me hace Cassini, relativamente independiente de si mi distinción entre las diversas fases de la historia de la filosofía de la ciencia es adecuada o no. Según él, yo establezco una oposición tajante entre una concepción sintáctica (que sería típica de la etapa clásica) y una semántica (típica de la última fase de nuestra historia). A esta supuesta oposición objeta Cassini que también la teoría clásica de los dos niveles que defienden Carnap, Hempel y otros autores clásicos, tiene un fuerte componente semántico, manifiesto en las llamadas "reglas de correspondencia". Y añade: "El problema principal de la concepción clásica no es que haya sido lingüística, ni sintactista, ni formalista, sino que nunca logró elucidar adecuadamente su aspecto semántico [de las teorías]". Pues bien, ésta es exactamente mi propia posición, como cualquiera puede percatarse en una lectura atenta de mi texto. Me permitiré citarme a mí mismo. Cuando inicio el tratamiento de las (mal) llamadas "concepciones semánticas" de van Fraassen, Suppe y Giere, advierto:

El apelativo de "concepción semántica" [referido a van Fraassen et al., y que para mí denota un subgrupo dentro de las concepciones modelísticas] puede ser, quizá, motivo de confusión, en la medida en que el rasgo común de esta familia de autores no es solamente señalar la importancia de los conceptos semánticos para analizar las teorías científicas (lo que ya habían señalado otros autores de la fase clásica de nuestra disciplina, como Carnap, Nagel, etc.), sino la predominancia absoluta de la visión semántica en detrimento de los análisis sintácticos, visión asociada a la preeminencia de la noción de modelo en sus diversas variantes. Calificaremos, pues, a estas concepciones de "semanticistas", más que de "semánticas". (p. 124)

Por lo demás, hago claro que esta preeminencia absoluta del análisis semántico es sólo característico de lo que llamo "concepciones 
semanticistas", no de todos los enfoques modelísticos. En particular, la metateoría estructuralista propone una reconstrucción de las teorías científicas en la que, si bien los componentes semánticos tienen un papel central, pone en juego también elementos pragmáticos, y en menor medida sintácticos. Por todo ello, no puedo sino concordar con lo que escribe Cassini: "la oposición entre una concepción semántica y una sintáctica no capta ninguna diferencia esencial. Es mejor distinguir entre una concepción de las teorías como conjuntos de proposiciones y otra que las concibe como colecciones de modelos". Éste es justamente el hilo conductor del último capítulo de mi libro; Cassini ha construido aquí artificialmente una divergencia con mi perspectiva que no existe.

Hasta aquí mi réplica a las críticas de Cassini. Para terminar, y como anuncio al comienzo de este artículo, quisiera hacer algunas breves observaciones a las propuestas alternativas que hace Cassini para escribir otra(s) futura(s) historia(s) de la filosofía de la ciencia. Él menciona cuatro enfoques posibles (supongo que la lista no es exhaustiva):

(1) Un enfoque que se concentre en la polémica realismo $v s$. antirrealismo.

(2) Un enfoque que se concentre en la filosofía de la experimentación.

(3) Un enfoque que trate del desarrollo institucional de nuestra disciplina.

(4) Una historia de la filosofía de las ciencias específicas.

Dado que, como he explicado más arriba, soy un adherente decidido de la "Tesis de la Subdeterminación de la Historiografía por la Historia", no tengo ningún problema de principio con que alguien (quizás el propio Cassini) emprenda la tarea de escribir una historia de nuestra disciplina desde alguna de esas otras perspectivas alternativas. (Emprenderla desde todas a la vez probablemente supere las posibilidades de un solo individuo.) En particular, hacerlo desde la perspectiva (3) me parecería muy interesante para lo que podría denominarse la "historia externa" de la filosofía de la ciencia. ${ }^{3}$ Respecto

${ }^{3}$ En mi libro sólo hago algunas referencias muy puntuales a esos aspectos de la historia. Está claro que mi perspectiva es esencialmente la de una historia de las ideas, "internista" si se quiere, lo cual no excluye, por supuesto, que pudiera ser complementada con una historia político-institucional. 
a la opción (4), tampoco tengo ninguna prevención de principio; el problema práctico, sin embargo, consistiría en encontrar un autor que pudiera, con igual competencia, escribir una historia de la filosofía de la física, de la biología, de la psicología, etc., a menos que el tratamiento quedara a un nivel muy superficial. Probablemente, una historia de la filosofía de las ciencias específicas sólo puede hacerse en equipo.

Confieso que tengo más problemas con las opciones (1) y (2) apuntadas por Cassini. La polémica realismo-antirrealismo apenas tuvo alguna incidencia en el desarrollo de la filosofía de la ciencia hasta bien entrados los años 1950; e incluso en las décadas posteriores fue sólo uno entre otros muchos temas discutidos por los filósofos de la ciencia. En consecuencia no me parecería convincente construir una historia de la filosofía de la ciencia que se centrara en dicha polémica.

Algo parecido, y aun en mayor medida, cabe decir de una historia que se centrara en la filosofía de la experimentación. Ésta cobró verdadera significación sólo a partir de los años 1980. Claro que podemos lamentar que las publicaciones de filosofía de la ciencia anteriores a 1980 ignoraran en gran medida el análisis filosófico de los experimentos; pero ésta es otra cuestión: el historiador debe atenerse a lo que realmente ocurrió ("wie es eigentlich gewesen", como decía el gran historiador decimonónico Leopold von Ranke), y no a lo que debiera haber ocurrido.

En resumen, si se quiere escribir una historia ("interna") de la filosofía (general) de la ciencia entre finales del siglo XIX y finales del XX, sigo creyendo que la mejor guía consiste en analizar lo que los diversos autores y enfoques tuvieron que decir acerca de la relación entre teoría y experiencia. Éste fue el hilo conductor que me guió en mi pequeña historia...

Recibido el 26 de diciembre de 2012; aceptado el 5 de febrero de 2013. 